Journal of Circuits, Systems, and Computers, Vol. 10, No. 5 \& 6 (2000) 315-316

(C) World Scientific Publishing Company

\title{
AUTHOR INDEX \\ VOLUME 10 (2000)
}

Ahmadi, M., see El-Feghi, I.

$10(2000) 219-228$

Ahmadi, M., see Raahemifar, K.

10 (2000) $27-65$

Bi, G. and Lian, S., Fast Algorithms for Generalized Discrete

Hartley Transform

10 (2000) $77-83$

Chen, R. M. M., see Jiang, Y.-L.

10 (2000) 205-218

Chung, K.-S. see Hong, S.

Costello, T. P. and Mikhael, W. B., A Novel Analytical Space-Variant Point Spread Function Model for Undercorrected Optical Systems

DeMara, R. F., see Motlagh, B. S.

Dubey, R. K., see Tiwari, M.

El-Feghi, I., Ahmadi, M., Miller, W. C., Sid-Ahmed, M. A., and Ramachandran, V., Design of Stable 3D Recursive Digital Filters Using 3-Variable Very Strictly Hurwitz Polynomial

He, Z., Li, K., Yang, L., and Shi, Y., TDMA Secure Communication Scheme Based on Synchronization of Chua's Circuits

10 (2000) 101-111

10 (2000) 305-313

$10(2000) 1-22$

10 (2000) $137-146$

10 (2000) 219-228

Hong, S., Kim, T., Narayanan, U., and Chung, K.-S., Decomposition of Bus-Invert Coding for Low-Power I/O

Jiang, Y.-L. and Chen, R. M. M., Multisplitting Waveform Relaxation for Systems of Linear Integral-Differential-Algebraic Equations in Circuit Simulation

10 (2000) 205-218

Kim, K.-S. and Lee, K., Low-Power 2D Motion Estimation Architecture with Complementary Embedded Memory Banks

Kim, T., see Hong, S.

10 (2000) 229-237

10 (2000) 101-111

Kim, T., see Kim, Y.-T.

Kim, Y.-T. and Kim, T., An Accurate Exploration of Timing and 10 (2000) 279-292 Area Trade-Offs in Arithmetic Optimization Using Carry-Save-Adders

Lau, K. T., see Ng, K. W.

10 (2000) 279-292

Lee, K., see Kim, K.-S.

10 (2000) $67-76$

10 (2000) 229-237

$\mathrm{Li}, \mathrm{K}$., see He, Z

10 (2000) $147-158$

Lian, S., see Bi, G.

10 (2000) $77-83$

Mikhael, W. B., see Costello, T. P.

10 (2000) 305-313

Mikhael, W. B., see Zhang, Q.

10 (2000) 293-303

Miller, W. C., see El-Feghi, I.

10 (2000) 219-228

Mishra, P. K., see Tiwari, M.

10 (2000) 137-146 
Mohamed, K. A. and Pap, L., Performance Analysis of Frequency-Hopped Packet Radio Networks with Spatially Distributed Users-Combined Error and Erasure Decoding Considered

10 (2000) 159-171

Motlagh, B. S. and DeMara, R. F., Performance of Scalabale Shared-Memory Architectures

Narayanan, U., see Hong, S.

Ng, K. W. and Lau, K. T., A Novel Adiabatic Register File Design

Ninov, V., see Ramachandran, V.

Nowrouzian, B., see Rao, V. M.

Pap, L., see Mohamed, K. A.

Parnichkun, M. and Samadi, V., Implementation of a Long Range LRF by Automatic Multi-Mode Measurement Scheme

Pierre, L., Induction-Oriented Verification of Replicated Architectures Described in VHDL

Premkumar, A. B., see Vinod, A. P.

Raahemifar, K. and Ahmadi, M., Novel Test Generation Algorithm for Combination Circuits

Ramachandran, V. and Ninov, V., 2D Zero-Phase FIR Filter Design with Nonuniform Frequency Sampling

Ramachandran, V., see El-Feghi, I.

Rao, V. M. and Nowrouzian, B., An Alternative Proof of Modified-Booth Recoding Algorithm Based on Number-Domain Transformations

Roy, K. C., see Tiwari, M.

Samadi, V., see Parnichkun, M.

Shi, Y., see He, Z.

Sid-Ahmed, M. A., see El-Feghi, I.

Tang, S.-H., Directed One-Time Password Authentication Scheme Based upon Discrete Logarithm

Tiwari, M., Dubey, R. K., Mishra, P. K., and Roy, K. C., Linear Predictive Coding in a New Binary System

Vinod, A. P. and Premkumar, A. B., A Memoryless Reverse Converter for the 4-Moduli Superset $\left\{2^{n}-1,2^{n}, 2^{n}+1,2^{n+1}-1\right\}$ Yang, L., see He, Z.

Zhang, Q. and Mikhael, W. B., Application of the Two-Dimensional Frequency Domain Least Squares Algorithm to Airborne Surveillance Radar Detection
$10(2000) 1-22$

$10(2000)$ 101-111

10 (2000) $67-76$

10 (2000) $239-277$

10 (2000) 23-26

10 (2000) 159-171

10 (2000) 113-135

10 (2000) 181-204

10 (2000) 85-99

10 (2000) 27-65

10 (2000) 239-277

10 (2000) 219-228

10 (2000) 23-26

10 (2000) 137-146

10 (2000) 113-135

10 (2000) 147-158

10 (2000) 219-228

10 (2000) 173-179

10 (2000) 137-146

10 (2000) 85-99

10 (2000) 147-158

10 (2000) 293-303 